\title{
Needs and Expectations of Parents Having Children with Cancer from Nurses
}

\author{
RASHA A. MOHAMMED, M.Sc.*; AFKAR R. MOHAMED, D.N.Sc.**; MARWA A. IBRAHIM, D.N.Sc.** and \\ WAEL Z. KHALED, M.D.*** \\ The Department of Head Nurse in Medical, National Cancer Institute*, Pediatric Nursing, Faculty of Nursing** and

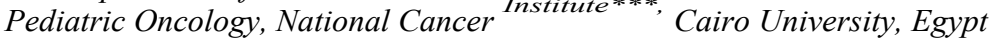

\begin{abstract}
Background: Parents dealing with childhood cancer face different stressors. The ability of parents to deal with these stressors may depend on the supportive care available to them.

Aim of Study: The current study aimed to determine the needs and expectations of parent of children with cancer from nurses.
\end{abstract}

Design: A descriptive exploratory research design was utilized for the current study.

Setting: The study was conducted in two pediatric wards in the National Cancer Institute (NCI) affiliated to Cairo University.

Sample: A convenient sample of 260 parents of children with cancer were participated in this study. Data was collected by using structured interview questionnaire sheet which consisted of two parts. Part I included personal data about parents of children with cancer, as well as their children, and medical history of the children. Part II included assessment sheet for needs of the parents (informational, psychosocial, physical, practical, and spiritual) and assessment sheet for expectations of the parents of children with cancer.

Results: The current study revealed that three quarters of parents were mothers accompanying the child to the hospital. The majority of children had leukemia, one third of them was in school age and male gender. There were statistically significant relation between parent's needs, expectations and their age and marital status. There were no statistical significant relation between parent's needs and their education and working status.

Conclusion: The current study concluded that the highest percentages of parents' needs were focused on informational, psychosocial, physical, practical, and spiritual. Parents have great expectations from nurses as they are the main source of support. In addition parents reported that they have unmet supportive needs from nurses.

Recommendations: The current study recommended that continuous assessment of the information needs of parents of

Correspondence to: Dr. Rasha A. Mohammed, The Department of Head Nurse in Medical, National Cancer Institute, Cairo University, Egypt children with cancer can help nurses in providing relevant and specific information according to parents' needs. Design a framework for supportive care needs may be useful in determine the parents' needs for proper planning to provide needs-based care.

Key Words: Parents - Children' cancer - Needs - Expectations - Nurses.

\section{Introduction}

CANCER refers to any one of a large number of diseases characterized by the development of abnormal cells that divide uncontrollably and have the ability to infiltrate and destroy normal body tissue [1] . Approximately 16,400 children and adolescents are diagnosed with a cancer every year in the United States [2]. Cancer is one of the leading causes of morbidity and mortality worldwide. Cancer is the second leading cause of death globally. Approximately $70 \%$ of deaths from cancer occur in low-and middle-income countries [3]. In Egypt, according to the Children's Cancer Hospital Egypt (CCHE), 8500 children in Egypt are estimated to be diagnosed with cancer every year [4]

The diagnosis and treatment of childhood cancer leads to many challenging, devastating, and stressful experiences for the child and their family members [5]. Parents of cancer children often provide complex care but often lack the information, support, and self-confidence necessary to perform these tasks. In addition, because many parents of cancer children experience moderate to high levels of stress and multiple demands on their time, their own physical and mental health may be negatively affected, and this can negatively affect the children's health outcomes [6]

Supportive care is described as "the provision of necessary services as defined by those living 
with or affected by cancer to meet their physical, psychosocial, informational and spiritual needs during the pre-diagnostic, diagnostic, treatment, and follow-up phases, while encompassing issues of survivorship, palliation, and bereavement" [7] The supports from healthcare professional, especially nurses are recognized as a major influencing factor in parents' ability to cope positively with their child's illness [8].

Unmet needs are defined broadly as problems requiring assistance that may occur in one or more life domains including physical, psychological, informational and spiritual domains [9]. Families are willing to help in the child's care but parents require clear guidance, information and support from nurses. Hidden expectations and unclear roles are stressful for families. Nurses need skills training, adequate resources and managerial support to meet families' needs appropriately, to establish true collaboration and to deliver optimal familycentered care [10]

Nurses play a prominent role in caring of children with cancer and their families. They support and educate the children and their families as they move through a stressful process. Nurses are challenged to maintain a high level of technical competence and an ability to provide the support required by the child and family [11]

\section{Significance of the study:}

According to National Cancer Institute incidence of invasive pediatric cancers is up $29 \%$ in the past 20 years. As well it does not discriminate, sparing no ethnic group, socio-economic class or geographic region. The needs and expectations of parents of children with cancer have been recognized as a major influencing factor in the wellbeing of children and their families. So determining the needs and expectations of parents of children with cancer will hopefully help to develop supportive strategy for caring of parents' and their children.

\section{Aim of the study:}

The main aim of the current study was to determine needs and expectations of parents of children with cancer from nurses.

\section{Research question:}

What are the needs and expectations of parents of children with cancer from nurses?

\section{Subjects and Methods}

Research design: A descriptive exploratory research design was conducted to carry out the current study.
Setting: The study was conducted in two pediatric wards in the National Cancer Institute (NCI) affiliated to Cairo University. Capacity of the two wards is 50 beds. Every word consists of 5 rooms, every room has 5 patients and one of them for male relative. One ward for free treatment and the other for insurance treatment.

Subjects: A convenient sample of 260 parents of children with cancer was included in the study. This study's sample size was determined based on the admitted children in the National Cancer Institute (NCI) in the Pediatric wards through the year 2013. All admitted children were 2166 cases in 2013 at NCI (NCI, 2014), so the sample size will be 260 .

$$
\mathrm{n}=\frac{t^{2} \mathrm{X} \mathrm{p}(1-\mathrm{p})}{\mathrm{m}^{2}}
$$

\section{Description:}

$\mathrm{n}=$ Required sample size .

$t=$ Confidence level of $95 \%$ (standard value of 1.96).

$\mathrm{p}=$ Estimated prevalence 0.2166 .

$\mathrm{m}=$ Margin of error of 5\% (standard value of 0.05 ).

$$
\mathrm{n}=\frac{1.96^{2} \times 0,2166(1-0,2166)=260}{0.05^{2}}
$$

\section{Inclusion criteria:}

- Parents of children with any type of cancer.

- Parents of children' aged from birth to 18 years old.

- All parents regardless their age and level of education.

\section{Exclusion criteria:}

- Parents of children with emergency conditions and end stages of cancer will be excluded.

\section{Tools of data collection:}

After reviewing the related literature, data was collected using structured interviewing questionnaire sheet which designed by the research investigator.

The structured interview questionnaire sheet consisted of two parts:

Part I: It included three sections:

A- Personal data about parents of children with cancer such as gender, age, educational level, employment, marital status, and family residence. 
B- Personal data about the children such as age, gender, rank and school enrollment.

C- Medical history of the child from medical record e.g. diagnosis, past and present history of illness/ problems, onset of disease, hospital stay, and current type of treatment.

Part II: It cover the following areas:

A- Assessment sheet for needs of the parents of children with cancer from nurses (informational, psychosocial, physical, practical, and spiritual).

- Informational needs from question 1 to question 13.

- Physical and practical needs from question 14 to question 19.

- Psychosocial needs from question 20 to question 33.

- Spiritual needs from question 34 to question 37.

B- Assessment sheet for expectations of the parents of children with cancer from nurses from question 38 to question 56.

The parents' response by yes or no and the total score was 56 then it was categorized into three categories:

- From 0-40\% parents have mild needs.

- From $>40-60 \%$ parents have moderate needs.

- From $>60 \%$ parents have higher needs.

Tools validity:

The tools were revised by three experts in pediatric oncology and pediatric oncology nursing to confirm content and face validity. Modifications on the tools were done in relation to appropriateness of the content, and sequence accuracy of items.

\section{Tools reliability:}

Reliability of the tools performed to confirm its consistency and was calculated statistically. The internal consistency was measured to identify the extent to which the items of the tools measure the same concept and correlate with each other. Reliability of the study's tools was done by Cronback's alpha coefficient test and it was (0.94).

\section{Pilot study:}

A pilot study was done on $10 \%$ of sample size (26 parents of children with cancer) at Pediatric wards in the National Cancer Institute (NCI) of Cairo University. The pilot study was conducted to test the feasibility of the study, the applicability of the tools as well as the time needed to fill the questionnaire sheet. The number of subjects in the pilot study was excluded from the total number of the study sample.

\section{Legal and ethical considerations:}

An acceptance of Ethical Committee of Faculty of Nursing, Cairo University was gained. All participants were informed about the aim of the study, benefits, and written agreement (consents) was obtained before data collection by the research investigator. The research investigator was emphasized that participation in the study is voluntary, and participant can refuse to participate in the study without any reason and obtained data only used for the research purpose. The participants were informed that the data will be anonymous and confidential. The researcher was informed parents of cancer child about their rights to withdraw from the study at any time without giving any reason and without any effect on their children care.

\section{Procedure:}

After reviewing literature and prepare the study tools by research investigator an official permission was obtained from both the Faculty of Nursing Ethical and Research Committee, Cairo University and Pediatric Unit Administrative authority at the National Cancer Institute. A written consent was obtained from parents of cancer child. An explanation of the aim, the nature of the study and tools were considered. Start to collect data about personal characteristics, and collect the data about children medical history from medical records. Assessment of parent's needs (information, physical and practical, psychosocial, and spiritual) and parents' expectations were collected through face to face interview to be able to include illiterate participants, insure higher response rate and to clarify misunderstood questions. Data were collected at pediatric wards in the National Cancer Institute (NCI) of Cairo University from October 2014 until June, 2015 in the patients' rooms. Questionnaire sheet was completed through an interviewing with parent of cancer children for 20 to 30 minutes.

\section{Data analysis:}

The data were collected, categorized, scored, tabulated, and analyzed using the recent Version (20.0) of statistical package for the social science (SPSS standard statistical book). The data were analyzed using descriptive statistics such as mean and standard deviation and frequency distribution. Correlation coefficient was used to determine direction and strength of the relationship of selected variables. Chi-square test, Person correlation analysis used for assessment of the inter-relationships 
and the significance relation between selected variables. The level of significance was set at $p$ less than 0.05 and highly significant was set at $p$ less than 0.00 .

\section{Limitations of the study:}

There were no special place for allowing the research investigator interviewing parents and children.

\section{Results}

Table (1) shows that near to three quarters $(73.8 \%)$ of children came with their mothers while the rest of them (26.2\%) came with their fathers. Regarding to the marital status of parents, the vast majority of parents $(90.8 \%)$ were married compared to the minority $(2.3 \%)$ were widow. The same table indicates that nearly half $(48.1 \%)$ of parents age ranged from 31 to 41 years, while the lowest percentage $(22.3 \%)$ their age ranged between 20 to 30 years with a mean of $37.53 \pm 8.11$ years old. Less than one third $(30.4 \%)$ of parents had secondary education while the lowest percentage (16.9\%) were highly educated. Regarding to parents working status, the result indicates that more than four fifth $(85.4 \%)$ of mothers were housewives, while the vast majority (88.2\%) of fathers were working. As well as, more than half $(56.2 \%)$ of family residence was rural area but more than two fifth $(43.8 \%)$ of family living in urban.

Table (1): Percentage distribution of parents' characteristics $(n=260)$.

\begin{tabular}{|c|c|c|}
\hline Item & No. & $\%$ \\
\hline \multicolumn{3}{|l|}{ Parents: } \\
\hline Mother & 192 & 73.8 \\
\hline Father & 68 & 26.2 \\
\hline \multicolumn{3}{|l|}{ Marital status of parents: } \\
\hline Married & 236 & 90.8 \\
\hline Divorced & 18 & 6.9 \\
\hline Widow & 6 & 2.3 \\
\hline \multicolumn{3}{|l|}{ Parent's age: } \\
\hline 20-30 years & 58 & 22.3 \\
\hline $31-41$ years & 125 & 48.1 \\
\hline$>41$ years & 77 & 29.6 \\
\hline Mean \pm SD & $37.53 \pm 8.11$ & \\
\hline \multicolumn{3}{|c|}{ Educational level of parents: } \\
\hline Higher education & 44 & 16.9 \\
\hline Secondary education & 79 & 30.4 \\
\hline Primary education & 63 & 24.2 \\
\hline Illiterate & 74 & 29.5 \\
\hline \multicolumn{3}{|l|}{$\begin{array}{l}\text { Working status of parents: } \\
\text { - Mothers }(n=192) \text { : }\end{array}$} \\
\hline Working & 28 & 14.6 \\
\hline Housewife & 164 & 85.4 \\
\hline \multicolumn{3}{|l|}{ - Fathers $(n=68)$ : } \\
\hline Working & 60 & 88.2 \\
\hline Not working & 8 & 11.8 \\
\hline \multicolumn{3}{|l|}{ Family residence: } \\
\hline Urban & 114 & 43.8 \\
\hline Rural & 146 & 56.2 \\
\hline
\end{tabular}

Table (2) reflects that about one third of children (32.8\%) aged from 6 to 10 years followed by $26.9 \%$ aged from birth to 5 years old while the minority of them $(15.1 \%)$ aged from 15 years to more with the mean age of children was $9.4 \pm 4.9$ years. One third of children $(33.8 \%)$ were ranked as the third child or more, while one quarter of them (25.8\%) was the first child. Additionally, the same table indicates that all families (100\%) have not another child with cancer. The study results reveals that the highest percentage of children $(80.4 \%)$ were in school while the minority of them (19.6\%) were absent from the school. More than half of children $(58.8 \%)$ were absent because there were underage, while about two fifth (41.2\%) of them were absent because of the disease and treatment related side effects. Regarding to degree of school, the result clarifies that nearly half of children $(46.4 \%)$ in primary school and the minority of children $(16.8 \%)$ in secondary school.

Table (2): Percentage distribution of child's data $(n=260)$

\begin{tabular}{|c|c|c|}
\hline Item & No. & $\%$ \\
\hline $\begin{array}{l}\text { Child's age: } \\
\text { Birth-5 years } \\
\text { 6-10 years } \\
11-15 \text { years } \\
>15 \text { years } \\
\text { Means } \pm S D\end{array}$ & $\begin{array}{l}70 \\
85 \\
66 \\
39 \\
9.42 \pm 4.94\end{array}$ & $\begin{array}{l}26.9 \\
32.8 \\
25.3 \\
15.1\end{array}$ \\
\hline $\begin{array}{l}\text { Child's rank: } \\
\text { Frist } \\
\text { Second } \\
\text { Third and more }\end{array}$ & $\begin{array}{l}67 \\
79 \\
114\end{array}$ & $\begin{array}{l}25.8 \\
30.4 \\
33.8\end{array}$ \\
\hline $\begin{array}{l}\text { Sibling with cancer: } \\
\text { Yes } \\
\text { No }\end{array}$ & $\begin{array}{l}0 \\
260\end{array}$ & $\begin{array}{l}0 \\
100\end{array}$ \\
\hline $\begin{array}{l}\text { Attendance of school: } \\
\text { Yes } \\
\text { No }\end{array}$ & $\begin{array}{l}209 \\
51\end{array}$ & $\begin{array}{l}80.4 \\
19.6\end{array}$ \\
\hline $\begin{array}{l}\text { Causes of absenteeism ( } \\
\text { Underage } \\
\text { Disease } \\
\text { Treatment side effect }\end{array}$ & $\begin{array}{l}30 \\
11 \\
10\end{array}$ & $\begin{array}{l}58.8 \\
21.6 \\
19.6\end{array}$ \\
\hline $\begin{array}{l}\text { Degree of school }(n=205 \\
\text { Nursery } \\
\text { Primary } \\
\text { Preparatory } \\
\text { Secondary }\end{array}$ & $\begin{array}{l}41 \\
97 \\
36 \\
35\end{array}$ & $\begin{array}{l}19.6 \\
46.4 \\
17.2 \\
16.8\end{array}$ \\
\hline
\end{tabular}

Fig. (1) shows that more than two fifth of child's diagnosis $(41.9 \%)$ was ALL while the minority $(8.9 \%, 6.5 \%$ \& $4.6 \%$ respectively) were brain, bone and wilms' tumors.

Regarding to the warning signs of children' cancer, Fig. (2) clarifies that less than one third (30.0\%) of warning signs was fever with unknown reason, followed by pain (29.6\%) and (21.9\%) for other warning signs such as headache, swollen lymph nodes, weakness and GIT disorder $(29.8 \%$, $26.3 \%, 24.6 \% \& 19.3 \%$ respectively). 


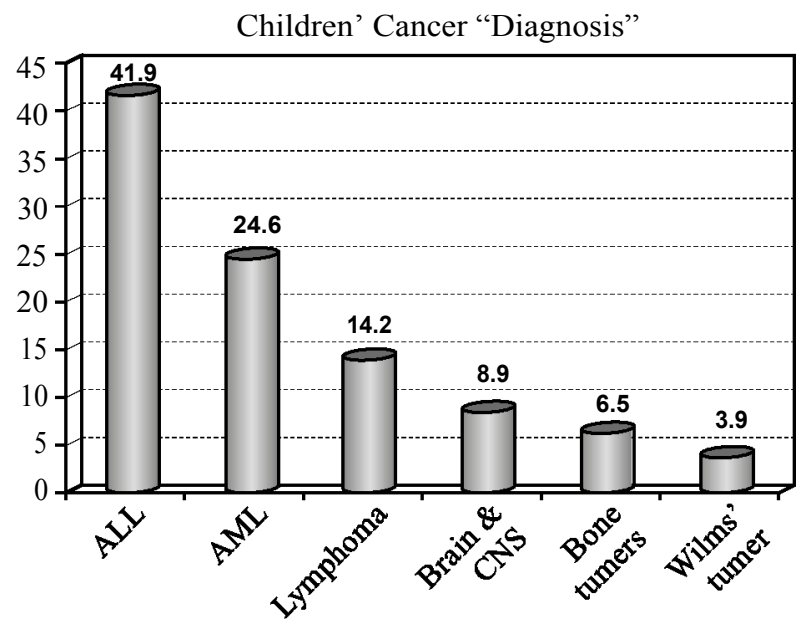

Fig. (1): Percentage distribution of children' cancer diagnosis $(n=260)$.

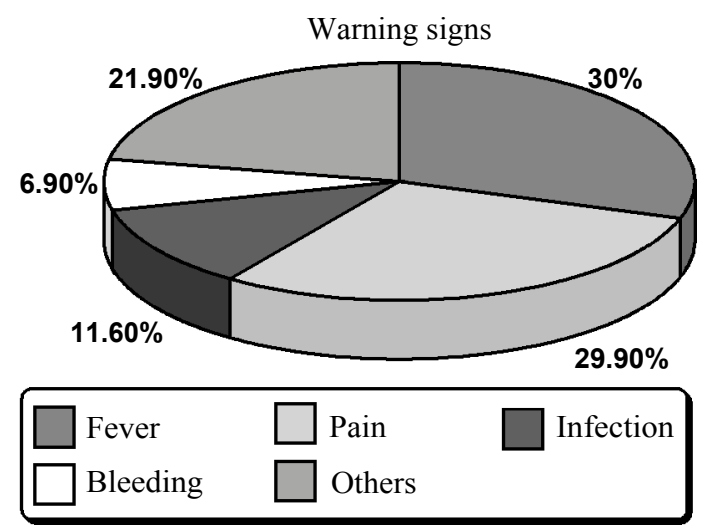

Fig. (2): Percentage distribution of children' warning signs $(n=260)$.

Table (3) shows that less than two thirds $(60 \%)$ of children stay between 1 to 20 days in hospital while the minority of them (3.5\%) stay more than 41 days in the hospital. More than three quarters $(77.7 \%)$ of children admitted to the hospital for treatment of chemotherapy while the minority $(3.5 \%)$ of them admitted to receive radiotherapy.

Table (3): Percentage distribution of child's characteristics according to medical history $(n=260)$.

\begin{tabular}{lll}
\hline Item & No. & $\%$ \\
\hline Duration of hospitalization: & & \\
1-20 days & 156 & 60.0 \\
21-41 days & 95 & 36.5 \\
>41 days & 9 & 3.5 \\
Current therapy: & & \\
Chemotherapy & 202 & 77.7 \\
Radiotherapy & 9 & 3.5 \\
Surgery & 31 & 11.9 \\
More than one treatment & 18 & 6.9 \\
\hline
\end{tabular}

Table (4) demonstrates that about three quarters; more or less of parents needed information about disease, investigations, treatment, preparations, side effects of treatment, and nutrition $(73.5 \%$, $78.8 \%, 75.4 \%, 76.5 \%, 71.2 \%$ and $73.1 \%$ respectively) for the child while about two thirds of them needed information about child response, family response, general hygiene, infection control, and prognosis $(68.8 \%, 68.5 \%, 67.7 \%, 67.7 \%, \& 65.8 \%$, respectively). Less two thirds $(61.5 \% \& 60.8 \%)$ of parents were in need for information related to health education and follow-up.

Table (4): Percentage distribution of parents' informational needs from nurses $(n=260)$.

\begin{tabular}{lcccc}
\hline & \multicolumn{2}{c}{ Yes } & \multicolumn{2}{c}{ No } \\
\cline { 2 - 5 } Item & No & $\%$ & No & $\%$ \\
\hline Informational needs: & & & & \\
$\quad$ Disease & 191 & 73.5 & 69 & 26.5 \\
Investigations & 205 & 78.8 & 55 & 21.2 \\
Treatment & 196 & 75.4 & 64 & 24.6 \\
Preparations & 199 & 76.5 & 61 & 23.5 \\
Child response & 179 & 68.8 & 81 & 31.2 \\
Side effects of treatment & 185 & 71.2 & 75 & 28.8 \\
Family response & 178 & 68.5 & 82 & 31.5 \\
Health education & 160 & 61.5 & 100 & 38.5 \\
Nutrition & 190 & 73.1 & 70 & 26.9 \\
General hygiene & 176 & 67.7 & 84 & 32.3 \\
Infection control & 176 & 67.7 & 84 & 32.3 \\
Prognosis & 171 & 65.8 & 89 & 34.2 \\
Follow-up & 158 & 60.8 & 102 & 39.2 \\
\hline
\end{tabular}

Table (5) clarifies that the vast majority of parents $(84.2 \%)$ needed the nurses assess the child general condition daily through physical examinations, more than three quarters of parents needed preparations for procedures, pain care, infection control measures, recording, reporting and physical activities $(79.2 \%, 73.8 \%, 78.8 \%, 79.6 \%$ and $76.2 \%$ respectively) for the child while more than two thirds of parent needed rooming sanitation and recreational therapy $(69.2 \%$ and $68.1 \%)$ for the child.

Table (5): Percentage distribution of parents' physical and practical needs from nurses $(n=260)$.

\begin{tabular}{lcccc}
\hline & \multicolumn{2}{c}{ Yes } & \multicolumn{2}{c}{ No } \\
\cline { 2 - 5 } Item & No & $\%$ & No & $\%$ \\
\hline Practical and physical needs: & & & & \\
$\quad$ Physical examinations & 219 & 84.2 & 41 & 15.8 \\
Preparations & 206 & 79.2 & 54 & 20.8 \\
Pain care & 192 & 73.8 & 68 & 26.2 \\
Infection control measures & 205 & 78.8 & 55 & 21.2 \\
Recording and reporting & 207 & 79.6 & 53 & 20.4 \\
Rooming sanitation & 180 & 69.2 & 80 & 30.8 \\
Recreational therapy & 177 & 68.1 & 83 & 31.9 \\
Physical activities & 198 & 76.2 & 62 & 23.8 \\
\hline
\end{tabular}

Regarding the psychosocial needs of parent from nurses, (Table 6) clarifies that less than three quarters of parents needed the nurse careful listen- 
ing, and respect feeling of the child $(71.2 \%$ and $73.5 \%$ ), more than sixty of parent needed decision making, cooperation, communication skills and coping strategies $(63.5 \%, 63.8 \%, 67.7 \%$ and $61.9 \%$ respectively) while more than half of them needed emotional support, connection with friends, school team connection, family members, sibling and consultations $(57.7 \%, 55.8 \%, 57.3 \%, 58.8 \%$ and $53.1 \%$ respectively) for the child.

Table (6): Percentage distribution of parents' psychosocial needs from nurses $(n=260)$.

\begin{tabular}{lllll}
\hline & \multicolumn{2}{c}{ Yes } & \multicolumn{2}{c}{ No } \\
\cline { 2 - 5 } Item & No & $\%$ & No & $\%$ \\
\hline Psychosocial needs: & & & & \\
$\quad$ Listen carefully & 185 & 71.2 & 75 & 28.8 \\
Emotional support & 150 & 57.7 & 110 & 42.3 \\
Decision making & 165 & 63.5 & 95 & 36.5 \\
Co-operative & 166 & 63.8 & 94 & 36.2 \\
Respect feeling & 191 & 73.5 & 69 & 26.5 \\
Communication skills & 176 & 67.7 & 84 & 32.3 \\
Coping strategies & 161 & 61.9 & 99 & 38.1 \\
Friends & 145 & 55.8 & 115 & 44.2 \\
School team & 149 & 57.3 & 111 & 42.7 \\
Family member and sibling & 153 & 58.8 & 107 & 41.2 \\
Consultations & 138 & 53.1 & 122 & 46.9 \\
\hline
\end{tabular}

The spiritual needs of parents from nurses in (Table 7) illustrates that more than less than three quarters of parents needed objectives and hope (72.7\% and $72.3 \%$ ), about sixty percentage of parents needed spiritual place and spiritual communication $(60,0 \%$ and $60.4 \%)$ while more than half of them $(55.0 \%)$ needed spiritual link with others.

Table (7): Percentage distribution of parents' spiritual needs from nurses $(n=260)$.

\begin{tabular}{lcccc}
\hline & \multicolumn{2}{c}{ Yes } & \multicolumn{2}{c}{ No } \\
\cline { 2 - 5 } Item & No & $\%$ & No & $\%$ \\
\hline Spiritual needs: & & & & \\
$\quad$ Spiritual place & 156 & 60.0 & 104 & 40.0 \\
Spiritual communication & 157 & 60.4 & 103 & 39.6 \\
Spiritual link with others & 143 & 55.0 & 117 & 45.0 \\
Objectives & 189 & 72.7 & 71 & 27.3 \\
Hope & 188 & 72.3 & 72 & 27.7 \\
\hline
\end{tabular}

It was evident from (Table 8) that more than seventy percentage of parents expected from nurses that applying child's rights, using role model, preventing complications, effective communications, keeping child privacy, equality in care, following hospital policies, being co-operative, documentations, respecting values and culture, and building trust relationships $(70.0 \%, 70.0 \%, 79.6 \%$, $73.5 \%, 78.8 \%, 77.3 \%, 77.7 \%, 70.8 \%, 72.3 \%$, $73.1 \%, 75.0 \%$ and $76.9 \%$ respectively), more than two third of parents $(69.2 \%)$ expected that the nurse demonstrate comprehensive nursing care while more than half of parents $(53.1 \%)$ expected the nurse attending workshop and conferences.

Table (8): Percentage distribution of parents' expectations from nurses $(n=260)$.

\begin{tabular}{lllll}
\hline & \multicolumn{2}{l}{ Yes } & \multicolumn{2}{l}{ No } \\
\cline { 2 - 5 } Item & No & $\%$ & No & $\%$ \\
\hline Parents' expectations: & & & & \\
Demonstrate comprehensive nursing care & 180 & 69.2 & 80 & 30.8 \\
Applying child's rights & 182 & 70.0 & 78 & 30.0 \\
Using role model & 182 & 70.0 & 78 & 30.0 \\
Preventing complications & 207 & 79.6 & 53 & 20.4 \\
Effective communications & 191 & 73.5 & 69 & 26.5 \\
Keeping child privacy & 205 & 78.8 & 55 & 21.2 \\
Equality in care & 201 & 77.3 & 59 & 22.7 \\
Following hospital policies & 202 & 77.7 & 58 & 22.3 \\
Being co-operative & 184 & 70.8 & 76 & 29.2 \\
Attending workshop and conferences & 138 & 53.1 & 122 & 46.9 \\
Documentations & 188 & 72.3 & 72 & 27.7 \\
Respecting values and culture & 190 & 73.1 & 70 & 26.9 \\
Building trust relationships & 200 & 76.9 & 60 & 23.1 \\
\hline
\end{tabular}

Regarding to the levels of parents needs and expectations, it was found in Fig. (3) that the highest percentage of parents $(70.4 \& 74.1 \%)$ had higher needs and expectations respectively.

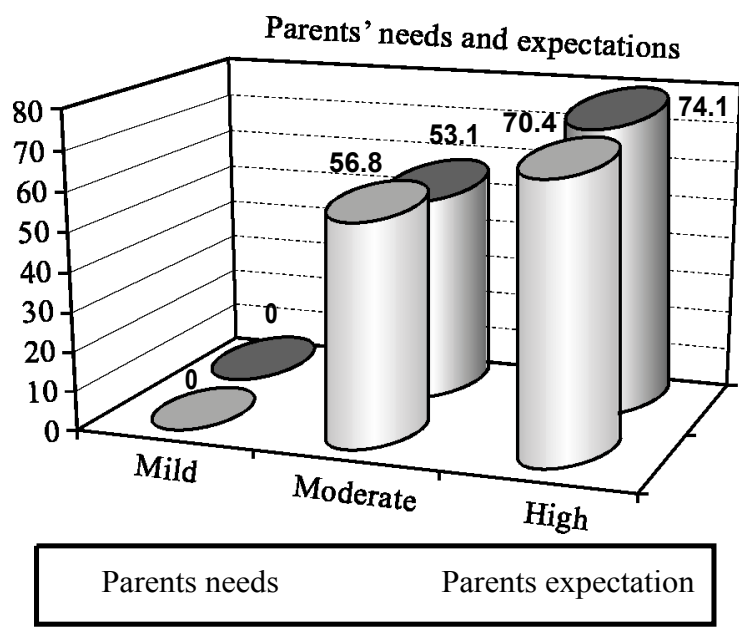

Fig. (3): Frequent distribution of total score of parents needs and expectations from nurses.

Table (9) proves that there were statistical significant relation between parents' age to informational, psychosocial needs and parent expectations $p=0.03, p=0.04$, and $p=0.04$ respectively. The same table displayed that no statistical significant relation between parents' age with physical, practical and spiritual needs $p=0.14$ and $p=0.60$.

The study results demonstrates that, there were no statistical significant relation between parents' education and parent informational, physical and practical, psychosocial, spiritual needs and parent 
expectations. It was detected that, there were statistical significant relation between parents' marital status and spiritual needs. On the same line, there were no statistical significant relation between parents' marital status and informational, physical and practical, psychosocial needs and parent expectations $(p=0.69, p=0.44, p=0.80$ and $p=0.43$ respectively). Moreover, the study results indicates that, there were no statistical significant relation between parents' occupation and parent informational, physical and practical, psychosocial, spiritual needs and parent expectations.

Table (9): Relationship between parents' age and their needs.

\begin{tabular}{lccc}
\hline & \multirow{2}{*}{$\begin{array}{c}\text { Parents' age } \\
\text { Item }\end{array}$} & \multicolumn{2}{c}{ Test } \\
\cline { 3 - 4 } & & $\mathrm{F}$ & $p$-value \\
\hline Informational needs & $37.5 \pm 8.1$ & 3.28 & $0.03^{*}$ \\
Physical and practical needs & & 1.98 & 0.14 \\
Psychosocial needs & & 3.15 & $0.04^{*}$ \\
Spiritual needs & & 0.50 & 0.60 \\
Parent expectations & & 3.07 & $0.04^{*}$ \\
\hline
\end{tabular}

*: Significant at $p \leq 0.05$.

Regarding to child's gender, (Table 10) shows that there were highly statistical significant relation between child's gender to physical and practical needs. Another statistical significant relation were detected between child's gender and informational needs and parent expectations $(p=0.04$ and $p=0.02$ respectively). On the other hand the same table indicated that there were no statistical significant relation between child's genders to psychosocial and spiritual needs $(p=0.16$ and $p=0.44$ respectively).

Table (10): Relationship between the children's gender and parents' needs.

\begin{tabular}{lcc}
\hline & \multicolumn{2}{c}{ Children's gender } \\
\cline { 2 - 3 } Item & $\mathrm{F}$ & $p$-value \\
\hline Informational needs & 4.03 & $0.04 *$ \\
Physical and practical needs & 7.73 & $0.00^{* *}$ \\
Psychosocial needs & 1.94 & 0.16 \\
Spiritual needs & 0.58 & 0.44 \\
Parent expectations & 5.36 & $0.02^{*}$ \\
\hline
\end{tabular}

* : Significant at $p \leq 0.05$.

**: Highly significant at $p \leq 0.05$.

The result of current study indicates that there were statistical significant relation between child's age and informational needs and psychosocial needs ( $p=0.02$ and $p=0.03$ respectively). The same table displays that there were no statistical significant relation between child' age and physical, practical, spiritual parents needs and parent expectation $(p=0.45, p=0.60$, and $p=0.07$ respectively).
It was found that, there were no statistical significant relation between child's degree of education and parents' informational, physical, practical, psychosocial, spiritual needs, and parent expectations.

\section{Discussion}

The current study results clarified that near to three quarters of parents were mothers while the rest of parents were fathers, that was in the same line with a cross-sectional survey on 411 parents of children receiving cancer treatment in Canada made by [21] about parents of children with cancer: Health-related quality of life, they found that the majority of parents were mothers. This finding may be due to mothers are the main caregiver in the Egyptian society providing physical care and psychosocial support to the ill child and other well children in the family. So, it is a challenging issue for mothers of child with cancer.

The current study results revealed that the vast majority of parents were married compared to the minority of them were widows. This result supported by American study made by [23] who studied Impact of caregiving for a child with cancer on parental health behaviors, relationship quality, and spiritual faith on 263 parents, and found that two third of parents were married. This finding may be related to that social status can deeply affect the needs for the family regarding educational, spiritual, psychosocial, and financial needs, moreover presence of parents enhance positive coping for children and family.

Based on the results of the current study, nearly half of parents' age ranged from 31 to 41 years while the lowest percentage their age ranged between 20 to 30 years with a mean of $37.53 \pm 8.11$ years old. In the same context, [7] studied the supportive care needs of parents with a child with a rare disease: Results of an online survey on 301 parents from Australia and New Zealand and found that $43.5 \%$ of parent aged from 35 to 44 years old. Parents' age might be affect their experience and coping strategies with childhood cancer.

In relation to parent's education, the results of current study indicated that less than one third of parents had secondary education while the lowest percentage were highly educated, which in the same line with [22] who studied Lebanese parents' experiences with a child with cancer on 12 parents and found that the majority of parents had primary education. Educational status of parents might be influence the cancer knowledge and adjustment skills. As well as level of education can affect 
cancer knowledge, understanding and coping with stress and anxiety.

Concerning parents working status, the results of the current study showed that the majority of mothers were housewives while the vast majority of fathers were working. This result is contradicted with the result of a study in Netherlands done by [24] who studied providing care for a child with cancer: A longitudinal study on the course, predictors, and impact of caregiving stress during the first year after diagnosis on 95 parents and found that the majority of mothers had a job. However, the diagnosis of childhood cancer have an impact on family financial status and sources of income. So, parents need to work more and for long times to meet the family financial needs while the mother take care of the children. Another point of view perceive that housewives can provide more psychosocial support for children than working mothers.

It was evident from the current study that more than half of family lived at rural area while the rest lived at urban. On the other hand, this result is contradicted with an Egyptian study held by [25] in the research about quality of life in Egyptian children with cancer on 67 parents and found that more than half of parents' residence was urban. The place of residence can have contributing factors with the child/parents and family coping with disease.

Regarding to gender of the studied children, the current study results clarified that two thirds of children were males. This result was supported by a study held by [26] in titled "parents' perceptions about their child's illness in pediatric cancer: Links with caregiving burden and quality of life" in Portugal on 277 parents, they found that the majority of children were males. In the same field many recent studies indicated that the majority of children with cancer were males. Having a male child, in our own culture, this is sometime a strong psychological factor for the parents.

It was found in the current study that about one third of children aged between 6 to 10 years, while the minority of them aged $<15$ years. This is correlate with the American study conducted by [27] searched about "sources of bother for hospitalized children and adolescents with cancer" on 50 children and found that more than half of children aged from 7 to 12 years. According to developmental theories of Piaga and Erikson school-age children are highly cognitive, active and need physical activity and peer approval. Lack of social and appropriate developmental activities, inability to practice daily living activities including school and play have been identified as major stressors for the child.

Findings of the current study showed that one third of children were ranked as the third child or more in the family, while one quarter was the first child in the family. On the same context, an Egyptian study made on 219 children and held by [29] who studied "acute lymphoid leukemia: Are Egyptian children adherent to maintenance therapy?", and found that near to three quarters of children had more than three siblings. The rank of child either the first, middle or the last could be affect the child interactions/relation within the family. It was evident from the current study that all families $(100 \%)$ have not another child with cancer. This may be due to the incidence of cancer in siblings is around $5 \%$.

In relation to attendance of school, the results of current study revealed that the highest percentage of children were in school while the minority of them were absent from the school. The causes of absenteeism from school were because children were underage, the effect of disease and treatment side effect. This might be due to cancer and treatment can disrupt a child's education, and the children requiring frequent, repeated hospitalization for the treatment as well as complications related the disease and treatment.

The majority of children's diagnosis was ALL, while the minority was Wilms' tumor. These results supported by a study in Guatemala in Central America made by [28] who indicated that near to two third of children were diagnosed with ALL. On the same context, [32] reported that according to cancer statistics, 2018 childhood leukemia accounts for $29 \%$ of all childhood cancers, and three quarters of which are lymphoid.

The current study's results clarified that less than one third of child warning signs was fever with unknown reason followed by pain compared with the lowest percentage was GIT disorder. Fever may be an indicator of presence of serious illness. This is because of the majority of cases were ALL and the minority was Wilms' tumor. From clinical experience, it was observed that the most common frequent complain of children with cancer are fever and pain.

In addition, the present study reflected that nearly two third of children stay between 1 to 20 days in the hospital while the minority of them stay more than 41 days. In the opposite side [30] 
studied "information-sharing between healthcare professionals, parents and children with cancer: More than a matter of informational exchange" in Ireland on 22 parents and found that length of stay of the majority of children in the hospital was from 3 to 6 days. The difference may be due to many factors such as time of diagnosis, stage of cancer, children condition on admission, availability of treatment and hospital environment.

The current study's results revealed that more than three quarter of children admitted to hospital for treatment with chemotherapy. This is confirmed with Swiss study on 309 parents done by [31] who studied "information needs in parents of long-term childhood cancer survivors" and found that the majority of children received chemotherapy. This could be interpreted the different uses of chemotherapy as curative treatment of some types of cancer and use to control spread of cancer. In addition, chemotherapy is the most frequent treatment for childhood leukemia which is the most common in children.

As regards to parent informational needs, the current study indicated that about three quarters of parents needed information about disease, investigations, treatment, preparations, side effects of treatment, and nutrition for the child while about two thirds of them needed information about child response, family response, general hygiene, infection control, and prognosis and less than two thirds of parents were in need for information related to health education and follow-up. In the same field, a study made in Johannesburg on 13 parents by [12] to study "the information needs of South African parents of children with cancer" highlighted that parent needed information about the disease, prognosis, treatment, and investigations. As well as recommended that continuous assessment of the information needs of parents of children with cancer can assist nurses in providing relevant and specific information according to parent's needs. Inadequate knowledge of disease, treatment, and complications is the main challenge among parents of children with cancer and may lead to lack of trust in health-care team and lack of children's cooperation with treatment. This may be due to lack of nurses' information about cancer, investigations, treatment, prognosis and follow-up or inability of them to assess parent informational needs.

The current study results revealed that the vast majority of parents needed the nurses to assess daily the child general condition through physical examinations. More than three quarters of parents needed preparations for procedures, pain care, infection control measures, recording, reporting and physical activities for the child, while more than two thirds of parent needed rooming sanitation and recreational therapy for the child. In the same context, [10] conducted a study about "families and health-care professionals' perspectives and expectations of family-centered care: Hidden expectations and unclear roles" on 18 parents and 18 nurses in Ireland. The author found that most parents expected to participate in their child's care and the nurses unable to deliver the basic physical care. This may be due to the shortage of nursing staff, engaging in more technical procedures or administration duties, supervising agency staff, skills training needs, inadequate resources and/or lack of monitoring process. Child's physical condition, pain related to procedures, and side effects of treatment have been identified as common stressors for parents over the course of child's treatment.

It was found in the current study that less than three quarters of parents needed the nurse careful listening, and respect feeling of the child, more than sixty of parent needed decision making, cooperation, communication skills and coping strategies while more than half of them needed emotional support, connection with friends, school team connection, family members, sibling and consultations for the child. These results were supported by [13] who studied psychosocial assessment as a standard of care in pediatric cancer and concluded that assessment of the psychosocial needs of the family is the first action necessary to determine subsequent steps for delivering interventions that address the psychosocial needs for families throughout the treatment trajectory. The current study results could be due to poor communication skills of nurses, work overload, lack of nurse's time, and mentoring student nurses as over duty. So, improving communication skills with parents, educating parents about all aspects of the child illness, and listening carefully to the particular needs will lead to better parent satisfaction and will contribute to better coping of parents and their children.

Findings of the current study revealed that, nearly three quarters of parents needed spiritual objectives and hope, about two third of parents needed spiritual place and spiritual communication while more than half of them needed spiritual link with others. This is consistent with previous findings by [14] who studied parents' experience of hope when their child has cancer: Perceived meaning and the influence of health care professionals in Northeast United States on 50 parents and concluded that, understanding parents' experiences 
validates the quality care and connections health care professionals make with children and families. This underscores the importance of education and support as a mean of instilling hope in parents, who are valued, critical members of their child's health care team.

On the same context, the study made by [15] about Understanding and responding to spiritual and religious needs of young people with cancer with 9 adolescent people, as well as 7 of their parents, found that Spiritual needs were classified under personal issues, relationships and attitude, and environment. Religious needs were identified as hope, resilience, and ritual, and connection, use of language and world view. And the researcher suggested that young people's spiritual and religious needs should be assessed on an ongoing basis, with staff being supported to undertake such assessment through the use of relevant tools, activities and a discussion of appropriate language. This could be due to poor nursing education about spiritual care and the effect of it on health outcome, failure of nurses to recognize children spiritual needs, and lack of understanding of the best ways to provide spiritual care.

It was evident from the current study that nearly three quarters of parents expected from nurses that applying child's rights, using role model, preventing complications, effective communications, keeping child privacy, equality in care, following hospital policies, being co-operative, documentations, respecting values and culture, being fair and building trust relationships, more than two third of parents expected that the nurse demonstrate comprehensive nursing care and confidentiality while more than half of parents expected the nurse attending workshops and conferences.

On the same context, a Turkish study on 100 mothers made by [5] they studied determination of social support needs and expectations of mothers of children with cancer and concluded that the majority of mothers expected social support from the nurses. The types of social support expected from nurses were mostly emotional and companionship. This may be due to work overload, lack of time, inadequate training to be a role model. So, nurses are in the ideal position to support children and families during hospitalization.

In addition, [16] in Brazil in their study about reactions of family members of children diagnosed with cancer: A descriptive study on 7 relatives, concluded among the expectations of the family with regard to the care of the nursing team, actions that will generate comfort, care and support are the most needed, as well as the provision of information using active listening, dialogue and explanations about the pathology, the treatment and the necessary care to provide for the needs of the children under oncologic treatment.

It was clear from the study's results that the highest percentage of parents had higher needs (as informational, physical practical, psychosocial, and spiritual) and higher expectations. This reflected that parents of children with cancer had massive needs and expectations from nurses.

The current study clarified that there were statistical significant relation between parents' age and informational needs, psychosocial needs and parent expectations from nurses. On the same context a study held by [17] who studied parent caregiver self-efficacy and child reactions to pediatric cancer treatment procedures and reported that parent age was significantly and negatively associated with parent self-efficacy for keeping the child calm before the treatment procedure and hiding emotions. Parents age could be interferes understanding with their needs and expectations.

The current study's results indicated that there was no statistical significant relation between parent's education and parent needs and expectations from nurses. This is contradicted with an Egyptian study held by [18] who detected positive significant relation between the caregiver's level of education and their knowledge and practices regarding leukemia. Level of education of parents is a key element in understanding and perception of informational, physical and practical, psychosocial, spiritual needs of their children with cancer.

Based on the results of the current study, there were statistical significant relation between parents' marital status and spiritual needs, while there were no statistical significant relation between parents' working status and all aspects of needs (informational, physical and practical, psychosocial, spiritual needs and parent expectations).

It was evident from the current study that there was statistical significant relation between child gender and parent informational, practical needs and parents' expectations and there no statistical significant relation between child gender to parents psychosocial needs. This result is supported by an Egyptian study held by [19] about cancer disclosureaccount from a pediatric oncology ward in Egypt and found that there was no significant association between psychosocial needs and child's gender. This could be interpreted that, all children especially 
male gender require a certain amount of "psychosocial support" as they grow and mature to help meet the emotional, social, mental, and spiritual needs.

The current study's results clarified that there was statistical significant relation between child age and parent informational and psychosocial needs. On the other hand a study made by [20] they studied "unmet care needs of parents of children with cancer in Jordan: Implications for bed-side practice", they found that parents' informational needs are independent of the age of the child. The researcher point of view is that the older the child the clear, suitable and adequate information increased child and parent satisfaction.

It was evident from the current study that, there was no statistical significant relation between child's degree of education and parents' informational, practical, psychosocial, spiritual needs, and parent expectations. This might be an indicator that the core of decision making and expressing all aspects of needs (informational, physical and practical, psychosocial, spiritual needs and parent expectations) are demonstrated by the parents. However the educational level of the children, the pediatric nurse should a certain that parents and children have the right to be involved in decision making and expressing their needs especially with the diagnosis of cancer.

\section{Conclusion:}

The current study concluded that parents experienced their child diagnosis as a crisis and reported that they have unmet supportive needs (informational, physical, practical, psychosocial, spiritual) from nurses and parents have great expectations of nurses as a main source of support. There were statistically significant relations between parent's needs, expectations and their age, marital status and child's gender. There were no statistically significant relations between parents' needs and their education and working status.

\section{Recommendations:}

Based on the findings of the current study, the following recommendations were suggested:

1- Continuous assessment of the information needs of parents of children with cancer can assist nurses in providing relevant and specific information according to parents' needs.

2- Simple booklets about child illness, treatment and its side effects should be available in pediatric words for raising parents' awareness. Uses of educational aids as audiovisual aids can help nurses to meet parent informational needs.

3- Elevating nurses' knowledge through sessions about child and parents needs and how to meet these needs.

4- Continuous training for nurses in all aspects of pediatric cancer and treatment is through educational programs and in-service training.

5- Design a framework for supportive care needs to determine the parents' needs for proper planning to provide needs-based care.

\section{References}

1- JOHNSON J.A., STOSKOPF C.H. and SHI L.: Comparative Health System. Jones \& Bartlett learning company, P: 27, 2018 .

2- ROBIN N.H. and FARMER M.B.: Pediatric Cancer Genetics. Epidemiology of childhood cancer. Elsevier, p: 1, 2018.

3- World Health Organization: Cancer. Available at www.who. int/news-room/fact-sheets/detail/cancer, 2017.

4- EL-MALLA H., KREICBERGS U., STEINECK G., ELBORAIL Y.E., WILDERANG U. and HELM N.Y.: Advances in Pediatric Oncology: A Five-Year Nation-Wide Survival follow-up at Children's Cancer Hospital in Egypt. Journal of Psychology and Clinical Psychiatry, 7 (4), 2017.

5- ALTAY N., KILICARSLAN E., SAR1 C. and KISECIK Z.: Determination of Social Support Needs and Expectations of Mothers of Children with Cancer. Journal of Pediatric Oncology Nursing, 31 (3): 147-53, 2014.

6- KENT E., ROWLAND J., NORTH L., LITZELMAN K., CHOU W., SHELBURNE N., TIMURA C., O'MARA A. and HUSS K.: Caring for caregivers and patients: Research and clinical priorities for informal cancer caregiving. Cancer, 122 (13): 1987-95, 2016

7- PELENTSOV L.J., LAWS T.A. and ESTERMAN A.J.: The supportive care needs of parents caring for a child with a rare disease: A scoping review. Disability and Health Journal, 8 (4): 475-91, 2015.

8- ILYAS N., IRAM M. and JAFRI S.A.: Psychosocial need of parents who have a child with cancer: A challenge for pediatric oncology nurses. Biomedical, 32 (2): 122-7, 2016.

9- BARATA A., WOOD W.A., CHOI S.W. and JIM H. Unmet Needs for Psychosocial Care in Hematologic Malignancies and Hematopoietic Cell Transplant. Springer Science + Business Media New York, 11: 280-7, 2016.

10- COYNE I.: Families and health-care professionals' perspectives and expectations of family-centred care: Hidden expectations and unclear roles. Health Expectations, 18, pp. 796-808, 2013.

11-JEMES S.R., NELSON K.A. and ASHWILL J.W.: Nursing care of children: Principles and practice. $4^{\text {th }}$ edition, Elsevier. Pp. 599-624, 2014.

12- MAREE J.E., PARKER S., KAPLAN L. and OOSTHUIZEN J.: The Information Needs of South African Parents 
of Children with Cancer. Journal of Pediatric Oncology Nursing, 33 (1): 9-17, 2016.

13- KAZAK A.E., ABRAMS A.N., BANKS J., CHRISTOFFERSON J., DiDONATO S., GROOTENHUIS M.A., KABOUR M., SWAIN A.M., PATEL S.K., ZADEH S. and KUPST M.J.: Psychosocial Assessment as a Standard of Care in Pediatric Cancer. Pediatr Blood Cancer, 62: S426-S459, 2015.

14- CONWAY M.F., PANTALEAO A. and POPP J.M.: Parents' Experience of Hope When Their Child Has Cancer: Perceived Meaning and the Influence of Health Care Professionals. Journal of Pediatric Oncology Nursing, 34 (6): 427-34, 2017.

15- DARBY K., NASH P. and NASH S.: Understanding and responding to spiritual and religious needs of young people with cancer. Cancer Nursing Practice, 13 (2): 32 7, 2014.

16- CARVALHO A.S., DEPIANTI J., SILVA L.F., AGUIAR R. and MONTEIRO A.C.M.: Reactions of family members of children diagnosed with cancer: A descriptive study. Online Brazil Journal of Nursing, 13 (3): 282-91, 2014.

17- PETERSON A.M., HARPER F.W., ALBRECHT T.L., TAUB J.W., OROM H., PHIPPS S. and PENNER L.A.: Parent Caregiver Self-Efficacy and Child Reactions to Pediatric Cancer Treatment Procedures. Journal of Pediatric Oncology Nursing, Vol. 31 (1): 18-27, 2014.

18- EL-SAWY M.M., ISMAIL G.M., MAGDY H. and ELSAMMAN G.A.: Knowledge and home practices of caregivers having children with leukemia attending National Cancer Institute, Cairo University. Med. Journal Cairo Univ., 81 (1): 601-8, 2013.

19- EL-MALLA H., STEINECK G., HELM N.Y., WILDERANG U., ELBORAIL Y.E., ELSHAMI M. and KREICBERGS U.: Cancer disclosure-account from a pediatric oncology ward in Egypt. Pycho-Oncology, 26: 679-85, 2017.

20- ARABIAT D.H. and ALTAMIMI A.: Unmet care needs of parents of children with cancer in Jordan: Implications for bed-side practice. Journal of Clinical Nursing, 22 (34): 531-9, 2013.

21- KLASSEN A.F., RAINA P., McINTOSH C., SUNG L., KLAASSEN R.J., O'DONNELL M., YANOFSKY R. and DIX D.: Parents of children with cancer: Which factors explain differences in health-related quality of life? International Journal of Cancer, 129 (5): 1190-8, 2011.

22- KHOURY M.N., HUIJER H.A. and DOUMIT M.A.: Lebanese parents' experiences with a child with cancer. European Journal of Oncology Nursing, 17 (1): 16-21, 2013.
23- WIENER L., VIOLA A., KEARNEY J., MULLINS L.L., BIEN S.S., ZADEH S., PATENAUDE A.F. and PAO M.: Impact of Caregiving for a Child With Cancer on Parental Health Behaviors, Relationship Quality, and Spiritual Faith: Do Lone Parents Fare Worse? Journal of Pediatric Oncology Nursing, 33 (5): 378-86, 2016.

24- SULKERS E., TOSSING W., BRINKSMA A., ROODBOL P., KAMPS W., STEWART R., SANDERMAN R. and FLEER J.: Providing care to a child with cancer: A longitudinal study on the course, predictors, and impact of caregiving stress during the first year after diagnosis. Psycho-Oncology, 24: 318-24, 2015.

25- FAWZY M., SALEH M., EL-WAKIL M., MONIR Z. and ELTAHLAWY E.: Quality of life in Egyptian children with cancer. Journal of Cancer Therapy, 4: 1256-61, 2013.

26- SALVADOR A., CRESPO C., MARTINS A.R., SANTOS S. and CANAVARRO M.C.: Parents' Perceptions about Their Child's Illness in Pediatric Cancer: Links with Caregiving Burden and Quality of Life. Springer Science + Business Media New York. Journal Child Family Studies, 24: 1129-40, 2015.

27- LINDER L.A. and SEITZ M.: Through Their Words: Sources of Bother for Hospitalized Children and Adolescents with Cancer. Journal of Pediatric Oncology Nursing, 34 (1): 51-64, 2017.

28- AGULNIK A., ROBLES L.N.M., FORBES P.W., VASQUEZ D.J.S., MACK R., KLUSSMANN F.A., KLEINMAN M. and GALINDO C.R.: Improved outcomes after successful implementation of a pediatric early warning system (PEWS) in a resource-limited pediatric oncology hospital. American Cancer Society, 123: 2965-74, 2017.

29- KHALEK E.R., SHERIF L.M., KAMAL N.M., GHARIB A.F. and SHAWKY H.M.: Acute lymphoblastic leukemia: Are Egyptian children adherent to maintenance therapy? Journal of Cancer Research and Therapeutics, 11 (1): 548, 2015.

30- COYNE I., AMORY A., GIBSON F. and KIERNAN G. Information-sharing between healthcare professionals, parents and children with cancer: More than a matter of information exchange. European Journal of Cancer Care, 25: 141-56, 2016.

31- VETSCH J., RUEEGG C., GIANINAZZI M.E., BERGSTRASSER E., WEID N.X. and MICHEL G.: Information needs in parents of long-term childhood cancer survivors. Pediatric Blood Cancer, 62: 859-66, 2015.

32- SIEGEL R.L., MILLER K.D. and JEMAL A.: Cancer statistics, 2018. Cancer Journal for Clinicians, 68 (1): 730, 2018. 


\section{إحتياجات وتوقعات آباء وآمهات الآطفال

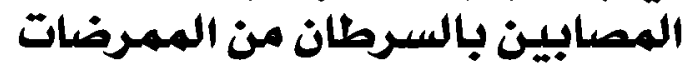

يواجه الآباء الذين يتعاملون مع سرطان الطفولة عوامل ضغط مختلفة. قد تعتمد قدرة الوالدين على التعامل مع هذه الضغوطات على الرعاية الداعمة المتاحة لهم.

كان هدف الدراسة الحالية هو تحديد إحتياجات وتوقعات آباءوآمهات الآطفال المصابين بالسرطان من الممرضات. خلمت الدراسة الحالية إلى آن الآباءوالآمهات آفادوا بآن لديهم إحتياجات داعمة غير ملباة من الممرضات وآن لديهم

توقعات كبيرة في الممرخات كمصدر رئيسى اللدعم. 